\title{
Uptake and predictors of contraceptive use in Afghan women
}

\author{
Mohammad H Rasooly ${ }^{1 *}$, Mohamed M Ali" ${ }^{2+}$ Nick JW Brown ${ }^{3,4+}$ and Bashir Noormal ${ }^{1+}$
}

\begin{abstract}
Background: Afghanistan has one of the world's highest fertility rates and, related to this, an infant mortality rate far higher than its South Asian neighbors. Contraception enhances family spacing, improves women's safety in child birth and, as a result, reduces infant and child mortality. Until recently, there has been a paucity of information on the comparative rates of contraceptive practices in the country and socioeconomic correlates of uptake. We aimed to elucidate the factors influencing the use of contraception in Afghanistan using recent, robust national data.

Methods: Using Afghanistan Mortality Survey (AMS) 2010 data, the distribution of Contraceptive Prevalence Rate (CPR) and correlates of contraceptive use among currently married women aged 15-49 years were explored. We initially summarised descriptive data on 25,743 married women and then derived predictors of the use of any form of contraception using a multiple logistic regression model.

Results: The prevalence of self-reported current use of any contraceptive method was $21.8 \%$ (95\% Cl: 20.4-23.4) at the national level though there was a wide variation in practice between provinces. Herat province in the West region had a highest contraceptive prevalence rate of $49.4 \%$ while Paktika in the Southeast region had the lowest CPR of 2\%. Multiple logistic regression analysis showed that a family size of greater than 6 living children strongly predicted contraceptive use (AOR 7.4 (95\% Cl:6.1-9.0)). Other independent predictors included: secondary or high level of education (AOR 2.1 (95\% Cl: 1.8-2.5)) and being in the wealthiest stratum (OR 2.1 (95\% Cl 1.5-3.0)). Rural residence predicted a lower use of contraception (AOR, 0.72; 95\% Cl: 0.56-0.92).
\end{abstract}

Conclusion: Contraceptive uptake rate was low overall with wide inter provincial variation. Strengthening female education, targeting married women in rural area and women with no education may enhance the effectiveness of National Family planning program in Afghanistan.

Keywords: Uptake, Predictors, Contraceptive, Afghan, Women

\section{Background}

Afghanistan is a landlocked country in south Central Asia. Administratively, the country is divided into eight geographical regions, 34 provinces and 398 administrative districts. The 2014/15 estimated population of the country is 26.5 million [1]. Most recent figures from 2010, though better than the previous (2003) data, estimate a total fertility rate of 5.1 child per women, a maternal mortality ratio of 327 per 100,000 live birth, an under-five mortality of 97 and infant mortality of 77 per 1000 live

\footnotetext{
* Correspondence: dochafez@yahoo.com

${ }^{\dagger}$ Equal contributors

'Afghanistan National Public Health Institute, Ministry of Public Health, Kabul, Afghanistan

Full list of author information is available at the end of the article
}

births all amongst the highest in the world. Only $26 \%$ of women age 15-49 ever attended school $[2,3]$.

Three decades of internecine war in Afghanistan have damaged the infrastructure, economy and social services. Women's access to health services has also, as a result, suffered and most women deliver without the presence of a skilled birth attendant $[4,5]$. There is also evidence to show that the continued high levels of fertility in Afghanistan accompanied with decline in maternal and child mortality may contribute to rapid growth in population, poverty and social issues [6,7]. This is likely to hinder the development of the country already struggling to recover its socioeconomic status. Previous literature suggests that higher education is associated with

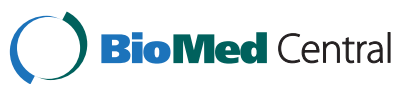

(c) 2015 Rasooly et al.; licensee BioMed Central. This is an Open Access article distributed under the terms of the Creative Commons Attribution License (http://creativecommons.org/licenses/by/4.0), which permits unrestricted use, distribution, and reproduction in any medium, provided the original work is properly credited. The Creative Commons Public Domain Dedication waiver (http://creativecommons.org/publicdomain/zero/1.0/) applies to the data made available in this article, unless otherwise stated. 
greater use of contraception but this has not been assessed in detail in Afghanistan.

In response to the sparse national data and inform future policy, the Afghanistan Mortality Survey (AMS) was conducted in 2010. Its aim was to provide information on the levels, trends, differentials, and causes of mortality and levels and differentials in related health and health care indicators. Recognising the potential health benefits of family planning, the AMS additionally collected data on fertility, marriage and family planning [2]. The National Family Planning Program was established in 2002 under the Reproductive Health Directorate of the Ministry of Public Health. Since then, family planning related activities have been integrated into a primary health package called Basic Package of Health Service (BPHS) and secondary and tertiary health package called the Essential Package of Hospital Services (EPHS) through more than 2000 public health facilities. In addition, family planning methods are also available through number of charities such as Marie Stopes International, the Afghan Family Guidance Association, Future Group and pharmacies.

Currently, oral contraceptive pills, the intra-uterine device (IUD), male condom and injectable contraceptives are widely available throughout the country. In some cities female sterilization and implant are also accessible. We sought to test this and other socioeconomic relationships using routinely collected and robust data. With this in mind, our study set out to provide a picture on distribution and correlation of contraceptive use in Afghanistan utilizing AMS 2010 data. The dataset is publically available at measure DHS website [8].

\section{Methods}

The Afghanistan Mortality Survey 2010 used the sampling frame prepared for Population and Housing Census (PHC) by Central Statistics Organization (CSO). It used a two-stage cluster sampling design to generate a nationally representative sample of households. In the first stage, the clusters were selected from the sampling frame. Households were then selected from each cluster allowing for stratification of urban and rural areas. The remoteness index is constructed using a similar methodology as the wealth index to measure the lack of infrastructure and/or distance services centers and it is constructed at the cluster level instead of the household level. The information is captured through a series of questions to the village leader or a knowledgeable person. For security reasons, the rural areas of Kandahar, Helmand, and Zabul provinces of South zone were excluded from the survey. Further details of the method used by region can be found in the main report of AMS 2010 [2].

Information for the household was obtained through personal interviews with an adult household member usually the head of the household. In the vast majority (96.7\% cases) men, husband or father in law, were the head of households with the household questionnaire. The questionnaires were based on the validated Demographic and Health Surveys Core Questionnaires, modified for use in Afghanistan. All staff were intensively trained for three weeks through both classroom lectures and field practice. Female surveyors interviewed all women 12-49 years of age within the selected households using the women's questionnaire. Maintaining the privacy and confidentiality during the interview were emphasized throughout the surveyors' training and field monitoring. Efforts were made to interview women in privacy uninfluenced by their husband or mother in law. Since the interviews were conducted by a female interviewer known to the community, respondents were able to disclose freely relevant information about the use of any contraceptive methods by themselves or their husbands.

The interview sought information on a woman's background (age, education, ethnicity, and marital status), their use of health services, on each of their children and the survival status of each child. The current use of contraceptive was assessed by the question "Are you currently doing something or using any method to delay or avoid getting pregnant? Where an affirmative was given, a further question" which method are you using?" was asked. Modern methods were defined as the oral contraceptive pill, IUD, injectable, condom, emergency contraception, implants and male and female sterilization. Traditional methods were as follows: periodic abstinence (rhythm), withdrawal and Lactation Amenorrhea Method (LAM).

\section{Data analysis}

The primary outcome measure was current use of any contraceptive method, a dichotomous variable, in nonpregnant married women. In the descriptive analysis, we illustrated the distribution of current contraceptive use by national, regions and provinces. Due to small numbers, data from Urozagan, Nimroz and Punisher (like the insecure regions) were not analysed further. To ensure representativeness across the country, data used were weighted according to survey sample. We then conducted exploratory analyses of the relationships between selected demographic and socioeconomic variables and current contraceptive use using current use of any contraception as a dichotmised outcome. Categorical and ordinal variables (place of residence, region, level of education, and experience of child death) were used as coded in the survey questionnaire, the two latent variables (wealth quintiles and remoteness) were computed from a set of variables collected in the household questionnaire using factor analysis and incorporated in the final survey dataset as categorical variables with five groups. In our analysis, however, we have grouped the three continuous variables age, age at marriage and number of living children 
using standard categories presented in most DHS surveys to ensure that there are enough numbers in each category for robust analysis. Bivariate outcomes and exposures were assessed by Chi squared test and potential predictors were assessed in a multiple logistic regression model using backward elimination method. The results of logistic regression analysis are given as adjusted odds ratios, with $95 \%$ confidence interval and $p$ values. All analysis was conducted in STATA version 13 taking into account the survey sample and cluster design and weights.

\section{Results}

\section{Descriptive analysis}

Members of 22,351 households were assessed for criteria for interview.

The analyses reported here are based on information on current use of contraceptive methods provided nonpregnant women aged between 15 and 49 years who numbered 25,743 . Use of any method of family planning was estimated as $22 \%$ with breakdown as follows (Table 1): injectable contraceptives (6.5\%), oral contraceptive pills (5.3\%); LAM (3.6\%); male condoms (1.7\%); the intrauterine contraceptive device (1.3\%); traditional methods (1.9\%) and female sterilization (1.4\%).

Table 1 shows the percent distribution of currently married women age 15-49 who were using specific family planning methods at the time of the survey, by province and regions. Herat province had the highest contraceptive prevalence rate (about 49\%), while Paktika had the lowest contraceptive prevalence rate of $2 \%$ (Figure 1). At the regional level, Central Highland, Capital and Western regions, have the largest percentage of currently married women currently using contraception, while the Southeast region had the smallest percentage.

Use of contraceptive varied by age group, the lowest use being in the youngest age group (14\%). Uptake increased successively by age group to $26.6 \%$ in the $35-$ 49 year group. There were significant differences in the current use of contraceptive methods among subgroups of currently married women. The use of family planning among urban women was double that of rural women (36 percent and 18 percent, respectively). Contraceptive use was more than twice as high in the Central Highlands as in the North, East and Northeast regions. There was a significant association between use of contraceptive and level of education with and increase from 20 percent among women with no formal education to 33 percent among women with primary education to 39 percent among women with secondary and higher education $(\mathrm{p}<0.001)$.

Wealth also was associated with the women's contraceptive use: only $17 \%$ of married women in the lowest wealth quintile were users compared to $33.9 \%$ in the highest wealth quintile (Table 2).
Table 1 Proportion of currently married women age 15-49 used contraceptive (\%) by province and region

Number of married Percent of currently $95 \% \mathrm{Cl}$ women age 15-49 using contraceptive interviewed

\begin{tabular}{|c|c|c|c|}
\hline \multicolumn{4}{|l|}{ Provinces } \\
\hline Kabul & 2,678 & 35.1 & $32.0-38.3$ \\
\hline Kapisa & 462 & 36.6 & $28.2-45.9$ \\
\hline Parwan & 615 & 40.9 & $35.7-46.3$ \\
\hline Wardak & 540 & 12.5 & 7.3-20.5 \\
\hline Logar & 378 & 34.2 & $27.2-42.0$ \\
\hline Nangarhar & 2,369 & 21.4 & $18.8-24.0$ \\
\hline Laghman & 601 & 18.1 & $12.6-25.0$ \\
\hline Baghlan & 815 & 15.0 & 11.8-19.0 \\
\hline Bamyan & 270 & 25.5 & $12.4-45$ \\
\hline Ghazni & 1,044 & 13.4 & $8.8-20$ \\
\hline Paktika & 667 & 2.1 & $0.6-7.0$ \\
\hline Paktya & 962 & 8.4 & $6.1-11.0$ \\
\hline Khost & 760 & 17.8 & $14.6-22.0$ \\
\hline Kunar & 1,171 & 6.2 & $4.1-9.0$ \\
\hline Nuristan & 356 & 5.7 & $2.7-12.0$ \\
\hline Badakhshan & 1,102 & 24.9 & $17.2-34.5$ \\
\hline Takhar & 1,001 & 6.9 & $4.9-10.0$ \\
\hline Kunduz & 904 & 10.2 & 7.8-13.0 \\
\hline Samangan & 385 & 14.0 & $8.9-21.0$ \\
\hline Balkh & 1,217 & 23.0 & $17.9-29.0$ \\
\hline Sari Pul & 559 & 15.4 & $12.5-19.0$ \\
\hline Ghor & 574 & 11.3 & 7.3-17.0 \\
\hline Daykundi & 645 & 39.8 & $31.0-49.0$ \\
\hline Jawzjan & 639 & 15.3 & $10.5-22.0$ \\
\hline Faryab & 1,162 & 6.7 & $4.5-10.0$ \\
\hline Badghis & 526 & 8.4 & $4.6-15.0$ \\
\hline Herat & 1,638 & 49.4 & $44.2-54.5$ \\
\hline Farah & 666 & 31.1 & $21.5-43$ \\
\hline \multicolumn{4}{|l|}{ Regions } \\
\hline North Eastern & 3,823 & 14.6 & $11.8-18.0$ \\
\hline Northern & 3,960 & 15.0 & $12.8-17.6$ \\
\hline Western & 3,405 & 33.0 & $28.0-38.0$ \\
\hline $\begin{array}{l}\text { Central } \\
\text { Highlands }\end{array}$ & 915 & 35.6 & $26.9-45$ \\
\hline Capital & 4,791 & 33.6 & $30.9-36.0$ \\
\hline Eastern & 4,497 & 15.8 & 13.4-18.0 \\
\hline Southern & 1,963 & 24.1 & 19.3-29.6 \\
\hline South Eastern & 2,388 & 9.6 & 7.4-12.0 \\
\hline Total & 25,743 & 21.8 & (20.4-23.4) \\
\hline
\end{tabular}




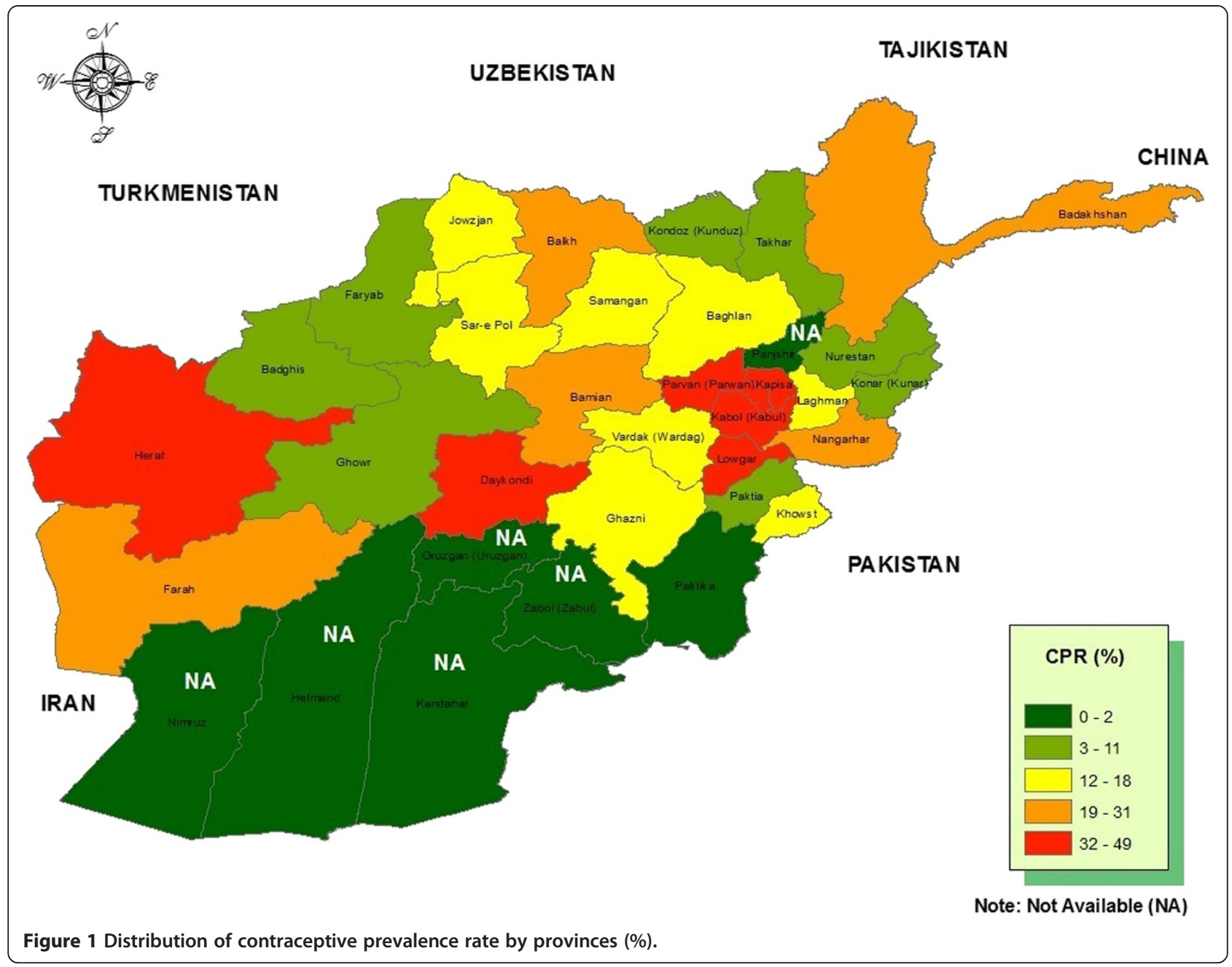

\section{Multivariate analysis}

We found that larger family size strongly predicted contraceptive use. The AOR for women with $6+$ living children was estimated as 7.4 (95\% CI: 6.1-9.0). Additional independent predictors included: greater age 0.81 (95\% CI: 0.69-0.95); wealth index 2.1 (95\% CI: $1.50-2.95$ ); place of residence 0.72 (95\% CI: 0.56-0.92); and education 2.10 (95\% CI: 1.80-2.45). Media exposure, remoteness of the households, age at first marriage were not associated with use of current use of contraception (Table 3).

\section{Discussion}

We found low rates of contraceptive use among married, non-pregnant women in Afghanistan with further reduction in uptake associated with the poverty, low level of education and younger age. Number of years of education might provide married women on the better awareness on advantages of birth spacing and use of contraceptive. Similarly, educated women could have positive health seeking behavior. The increase number of living children as mentioned strongly associated with use of contraceptive among currently married women. The findings from the studies conducted in two cities of Pakistan were also found that number of living children was strongly associated with use of contraceptive methods $[9,10]$.

Though uptake has increased since previous surveys (perhaps a result of the Basic Package of Health Services (BPHS) introduced in 2003), male use has stalled with no increase in the use of the male condom from 2006-2011 [11-13]. This is probably a reflection of the fact that family planning information and services in Afghanistan are not targeted towards men but have been provided in the context of maternal and child health. Although contraceptive use has increased both nationally and in the provinces in recent years, women who were living in rural area are less likely to use any contraceptive methods than their urban counterparts

Despite the proportion of contraceptive use was increasing overall, the reliance on the traditional methods remained constant during last decade. The low rates of sterilisation could be because it is not part of National 
Table 2 Current use of contraceptive by socio-demographic characteristics among married women 15-49 (Bivariate analysis)

\begin{tabular}{llll}
\hline n & $\begin{array}{l}\text { Contraceptive } \\
\text { prevalence rate }\end{array}$ & $95 \% \mathrm{Cl}$ & P. Value \\
\hline
\end{tabular}

\section{Residence}

Urban

$4,934 \quad 36.4$

Rural

$20,809 \quad 18.4$

$33.9-39.0$

$<0.001$

Region

$\begin{array}{lllll}\text { North Eastern } & 3,823 & 14.6 & 11.8-18.0 \quad<0.001 \\ \text { Northern } & 3,960 & 15.0 & 12.8-17.6 & \\ \text { Western } & 3,405 & 33.0 & 28.0-38.0 & \\ \text { Central Highland } & 915 & 35.6 & 26.9-45.0 & \\ \text { Capital } & 4,791 & 33.6 & 30.9-36.0 & \\ \text { Eastern } & 4,497 & 15.8 & 13.4-18.0 \\ \text { Southern } & 1,963 & 24.1 & 19.3-29.6 & \\ \text { South Eastern } & 2,388 & 9.6 & 7.4-12.0\end{array}$

Education

No education/ $\quad 22914 \quad 20.1$

Madrasa

$\begin{array}{lll}\text { Primary } & 1,485 & 33.0\end{array}$

Secondary/Higher $\quad 1,344 \quad 39.1$

Age group

$\begin{array}{lll}15-24 & 7,221 & 14.0 \\ 25-34 & 9,220 & 23.2 \\ 35-49 & 9,302 & 26.6\end{array}$

Age at first marriage

$\begin{array}{lll}\text { Less than 16 } & 9,035 & 24.7 \\ 16-19 & 8,892 & 21.2 \\ 19+ & 7,816 & 19.3\end{array}$

Number of living children

$\begin{array}{lll}0-1 & 5,800 & 7.4 \\ 2-3 & 6,434 & 21.0 \\ 4-5 & 6,033 & 27.3 \\ 6+ & 7,476 & 29.4\end{array}$

Child death experiences

$$
\begin{array}{lll}
\text { No } & 20,005 & 20.9 \\
\text { Yes } & 5,738 & 25.1
\end{array}
$$

Remoteness

Most remote

$6,621 \quad 18.4$

2

$7,255 \quad 22.9$

3

4

Least remote

$5,110 \quad 21.3$

$4,189 \quad 21.6$

$2,568 \quad 29.3$

Wealth quintiles

Poorest

$5,115 \quad 17.0$
$16.8-20.0$

$7.4-12.0$

$18.6-21.7<0.001$

29.9-36.0

$35.7-42.6$

$12.6-15.6<0.001$

21.3-25.0

24.7-28.6

$22.7-26.9<0.001$

$19.5-23.0$

17.8-20.9

6.5-8.5 < $<0.001$

19.2-22.9

25.0-29.6

27.2-31.7

$19.4-22.5<0.001$

23.1-27.0

$15.9-21.0 \quad 0.0019$

19.8-26.0

18.4-24.5

18.0-25.7

25.2-33.8

$14.1-20.5<0.001$
Table 2 Current use of contraceptive by socio-demographic characteristics among married women 15-49 (Bivariate analysis) (Continued)

\begin{tabular}{lllll} 
Poorer & 5,328 & 19.8 & $17.5-22.0$ & \\
Middle & 5,057 & 17.8 & $15.7-20.0$ & \\
Richer & 5,153 & 20.7 & $18.6-22.9$ & \\
Richest & 5,090 & 33.9 & $31.5-36.0$ & \\
Mass media exposure & & & & \\
No exposure & 6,864 & 17.0 & $14.6-19.6$ & $<0.001$ \\
Radio only & 12,301 & 19.5 & $17.8-21.0$ & \\
Radio and TV & 6,578 & 31.3 & $29.1-33.5$ & \\
\hline
\end{tabular}

\begin{tabular}{|c|c|c|c|}
\hline & AOR & $95 \% \mathrm{Cl}$ & $p$ value \\
\hline \multicolumn{4}{|l|}{ Residence } \\
\hline Urban & 1.00 & & \\
\hline Rural & 0.72 & $0.56-0.92$ & 0.007 \\
\hline \multicolumn{4}{|l|}{ Region } \\
\hline North Eastern & 1.00 & & \\
\hline Northern & 0.97 & $0.72-1.31$ & 0.843 \\
\hline Western & 2.90 & $2.06-4.08$ & $<0.001$ \\
\hline Central Highland & 4.07 & $2.48-6.70$ & $<0.001$ \\
\hline Capital & 1.84 & $1.36-2.48$ & $<0.001$ \\
\hline Eastern & 0.89 & $0.65-1.20$ & 0.440 \\
\hline Southern & 1.42 & $0.97-2.06$ & 0.068 \\
\hline South Eastern & 0.51 & $0.35-0.75$ & 0.001 \\
\hline \multicolumn{4}{|l|}{ Education } \\
\hline No education/Madrasa & 1.00 & & \\
\hline Primary & 1.60 & $1.36-1.81$ & $<0.001$ \\
\hline Secondary/Higher & 2.10 & $1.80-2.45$ & $<0.001$ \\
\hline \multicolumn{4}{|l|}{ Age group } \\
\hline $15-24$ & 1.00 & & \\
\hline $25-34$ & 0.89 & 0.8-1.01 & 0.070 \\
\hline $35-49$ & 0.81 & $0.69-0.95$ & 0.012 \\
\hline \multicolumn{4}{|l|}{ Number of living children } \\
\hline $0-1$ & 1,00 & & \\
\hline $2-3$ & 3.72 & $3.23-4.30$ & $<0.001$ \\
\hline $4-5$ & 5.77 & $4.87-6.84$ & $<0.001$ \\
\hline $6+$ & 7.40 & $6.06-9.02$ & $<0.001$ \\
\hline \multicolumn{4}{|l|}{ Wealth quintiles } \\
\hline Poorest & 1.00 & & \\
\hline Poorer & 1.33 & $1.06-1.69$ & 0.016 \\
\hline Middle & 1.39 & $1.05-1.84$ & 0.022 \\
\hline Richer & 1.67 & $1.22-2.27$ & 0.001 \\
\hline Richest & 2.10 & $1.50-2.95$ & $<0.001$ \\
\hline
\end{tabular}

Table 3 Factors associated with use of contraceptive by socio-demographic characteristics in married women 15-49 (Multivariate analysis) 
Family Planning Program in Afghanistan, low availability outside cities and, given the conservative nature of Afghan society, less likely to be acceptable to religious leaders.

Our findings are compatible with those from other studies. A comparative study of contraceptive use in Nigeria revealed similar rural urban disparity in use of contraceptive [14]. In the former Soviet Union, Janevic et al. showed that women from poorest communities less likely to use contraceptive methods than their wealthier counterparts [15] a finding that has also been made in Malawi [16]. Our study discovered that educational level was positively associated with contraceptive use in Afghanistan and women with no or informal education were the least likely to use any contraceptive methods than women with secondary and higher education. Similar patterns were also observed in elsewhere [17-24]. Number of years of education might provide married women on the better awareness on advantages of birth spacing and use of contraceptive. Similarly, educated women could have positive health seeking behavior.

The study had number of strengths. It was based on near complete national coverage and represents by far the most comprehensive sample to date.

There were a number of limitations. As this study was cross-sectional survey, a definite causal relationship between the outcome measure and the exploratory variables could not be established. There may also have been biases resulting from the exclusion of a third of the rural areas in the South and, possibly, despite great sensitivity on the part of the interviewers, a reluctance to divulge information amongst the women. We were also unable to establish qualitative reasons for use and nonuse of contraception again perhaps a reflection of cultural sensitivities.

\section{Conclusion}

Rates of contraceptive uptake are low in Afghanistan and rural, uneducated women are less likely to use any of the standard methods. The family planning programme must expand its activities to inform this vulnerable group, involve men and promote longer acting or permanent contraception such as the IUD and female sterilization.

\section{Abbreviation \\ AMS: Afghanistan Mortality Survey; AOR: Adjusted odds ratios; BPHS: Basic package of health services; CPR: Contraceptive prevalence rate; CSO: Central Statistics Organization; DHS: Demographic and Health Survey; EAs: Enumerated areas; PHC: Population and Housing Census; PSU: Primary sampling unit.}

\section{Competing interests}

The authors declare that they have no competing interests. The views expressed in this paper are those of the authors and do not necessarily reflect the views of $\mathrm{WHO}$ and their institutions.

\section{Authors' contributions}

MHR conceived the study. The first author collected the data and draft the manuscript. MA contributed on advanced data analysis. NB contributed and helped to edit the manuscript. BN help in drafting the manuscript. All authors read and approved the final manuscript.

\section{Authors' information}

Mohammad H Rasooly, Senior Technical Advisor/National Influenza Surveillance Coordinator MD, MSc, Afghanistan National Public Health Institute, Ministry of Public Health, Kabul-Afghanistan.

Mohamed M. Ali, Coordinator PhD, Health Information and Statistics, Department of Information, Evidence and Research, World Health Organization, Regional Office for Eastern Mediterranean, Cairo, Egypt Nick JW Brown, Consultant Paediatrician, Salisbury District Hospital, Salisbury, Wiltshire, UK. Visiting fellow, Southampton University Hospitals Trust, University of Southampton, Southampton, Hampshire, UK. Visiting faculty, Aga Khan University, Karachi Pakistan.

Bashir Noormal, Director General MD, MPH, Afghanistan National Public Health Institute, Ministry of Pulic Health Kabul Afghanistan.

\section{Acknowledgments}

The authors would like to thanks Ministry of Public health and ICF Macro for providing AMS dataset for the secondary data analysis. We also sincerely thanks World Health Organization country and EMRO office for their generous support in conducting the secondary data analysis meeting.

\section{Author details}

${ }^{1}$ Afghanistan National Public Health Institute, Ministry of Public Health, Kabul, Afghanistan. ${ }^{2}$ Eastern Mediterranean Regional Office, World Health Organization, Cairo, Egypt. 'Salisbury District Hospital, Salisbury, Wiltshire, UK. ${ }^{4}$ Aga Khan University, Karachi, Pakistan.

Received: 15 June 2014 Accepted: 30 January 2015

Published online: 13 February 2015

\section{References}

1. Central Statistic Organization, population estimation, [http://cso.gov.af/en/ page/demography-and-socile-statistics/demograph-statistics/3897]

2. Afghan Public Health Institute, Central Statistics Organization, ICF Macro, Indian Institute of Health Management Research \& World Health Organization Regional Office for the Eastern Mediterranean, Afghanistan Mortality Survey 2010 [http://dhsprogram.com/publications/publicationfr248-other-final-reports.cfm]

3. Bartlett LA, Mawji S, Whitehead S, Crouse C, Dalil S, lonete D, et al. Where giving birth is a forecast of death: maternal mortality in four districts of Afghanistan, 1999-2002. Lancet. 2005;365(9462):864-70. doi:10.1016/ S01406736(05)71044-8.

4. Maurice J. WHO heads efforts to restore Afghanistan's shattered health. Bull World Health Organ. 2001;79(12):1174.

5. Mayhew M, Hansen PM, Peters DH, Edward A, Singh LP, Dwivedi V, et al. Determinants of skilled birth attendant utilization in Afghanistan: a cross-sectional study. Am J Public Health. 2008;98(10):1849-56.

6. United Nation, Department of Economic and Social Affairs, World Population Prospects: The 2012 Revision, mortality data available at http://esa.un.org/unpd/wpp/Excel-Data/mortality.htm

7. United Nation, Department of Economic and Social Affairs, World Population Prospects: The 2012 Revision, Fertility data available at http://esa.un.org/unpd/wpp/Excel-Data/fertility.htm

8. The DHS program, Demographic and Health Survey, Survey Dataset Files, Afghanistan : Special, 2010 available at http://dhsprogram.com/data/ dataset/Afghanistan_Special_2010.cfm?flag=0

9. Lasee A, McCormick JB. Demographic and socio-economic determinants of contraceptive use in a low income community of Karachi. JPMA. 1996;46:228.

10. Ali S, Rozi S, Mahmood MA. Prevalence and factors associated with practice of modern contraceptive methods among currently married women in district naushahro feroze. JPMA. 2004;54:461.

11. ICON-INSTITUTE. National risk and vulnerability assessment 2007/08: A profile of Afghanistan, main report. Cologne, 2009

12. Johns Hopkins University Bloomberg School of Public Health (JHUBSPH), \& Indian Institute of Health Management Research (IIHMR). Afghanistan health 
survey: Estimates of priority health indicators. Kabul: Ministry of Public Health; 2006.

13. Central Statistics Organization \& United Nations Children's Fund Afghanistan multiple indicator cluster survey 2010-2011: Final report. Kabu

14. Adebimpe Wasiu O, Asekun-Olarinmoye Esther O. A comparative study of contraceptive use among rural and urban women in osun state, Nigeria. Int J Trop Dis Health. 2012;2(3):214-24.

15. Janevic T, Sarah PW, Leyla I, Elizabeth BH. Individual and community level socioeconomic inequalities in contraceptive use in 10 Newly Independent States: a multilevel cross-sectional analysis. Int J Equity Health. 2012;11:69.

16. Adebowale SA, Adedini SA, Ibisomi LD, Palamuleni ME. Differential effect of wealth quintile on modern contraceptive use and fertility: evidence from Malawian women. BMC Women's Health. 2014:14:40.

17. Babalola S, Fatusi A Determinants of use of maternal health services in Nigeria - Looking beyond individual and household factors. BMC Pregnancy Childbirth 2009, 9(43).

18. Beekle AT, McCabe C. Awareness and determinants of family planning practice in Jimma, Ethiopia. Int Nurs Rev. 2006;53(4):269-76.

19. Fantahun M. Comparative study of the characteristics of family planning service users and non-users in northwest Ethiopia. Afr J Reprod Health. 2006;10(1):62-70

20. Sueyoshi S, Al-Khozahe HO, Ohtsuka R. Effects of reproduction norms on contraception practice among Muslim women in Amman, Jordan. Eur J Contracept Reprod Health Care. 2006;11:138-45.

21. Al Riyami A, Afifi M, Mabry RM. Women's autonomy, education and employment in Oman and their influence on contraceptive use. Reprod Health Matters. 2004;12:144-54.

22. Cindoglu D, Sirkeci I, Sirkeci RF. Determinants of choosing withdrawal over

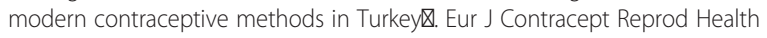
Care. 2008;13:412-21.

23. Bangladesh Demographic and Health Survey: Contraception in Bangladesh: a review of 22 years of family planning and projection for the next 17 years. Dhaka 1998.

24. Koc I. Determinants of contraceptive use and method choice in Turkey. J Biosoc. 2000;32:329-42.

\section{Submit your next manuscript to BioMed Central and take full advantage of:}

- Convenient online submission

- Thorough peer review

- No space constraints or color figure charges

- Immediate publication on acceptance

- Inclusion in PubMed, CAS, Scopus and Google Scholar

- Research which is freely available for redistribution 